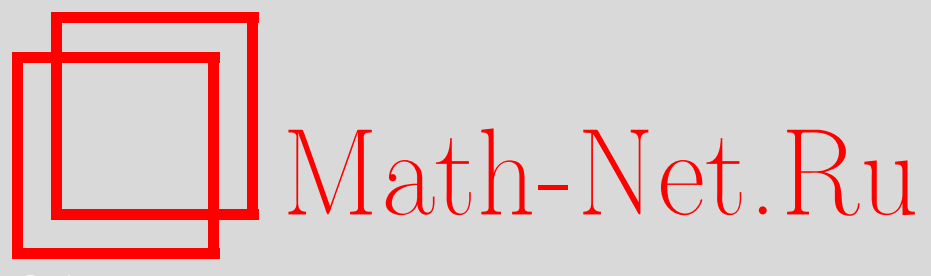

Д. В. Аносов, В. С. Афраймович, Л. А. Бунимович, С. В. Гонченко, В. З. Гринес, Ю. С. Ильяшенко, А. Б. Каток, С. А. Кащенко, В. В. Козлов, Л. М. Лерман, А. Д. Морозов, А. И. Нейштадт, Я. Б. Песин, А. М. Самойленко, Я. Г. Синай, Д. В. Трещёв, Д. В. Тураев, А. Н. Шарковский, А. Л. Шильников, Леонид Павлович Шильников (некролог), УМH, 2012, том 67, выпуск $3,175-178$

DOI: https://doi.org/10.4213/rm9481

Использование Общероссийского математического портала Math-Net.Ru подразумевает, что вы прочитали и согласны с пользовательским соглашением http://www . mathnet.ru/rus/agreement

Параметры загрузки:

IP : 3.91 .87 .62

26 апреля 2023 г., 13:24:28

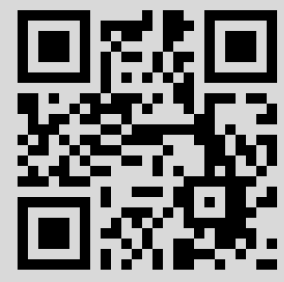




\section{Леонид Павлович Шильников}

26 декабря 2011 г. ушел из жизни замечательный математик, один из крупнейших специалистов по теории динамических систем и теории бифуркаций, лауреат премий имени А. М. Ляпунова Российской академии наук и имени М. А. Лаврентьева Национальной академии наук Украины, гумбольдтовский профессор, заведующий отделом дифференциальных уравнений НИИ прикладной математики и кибернетики Нижегородского университета профессор Леонид Павлович Шильников.

Леонид Павлович родился 17 декабря 1934 г. в г. Котельниче Кировской области в семье рабочих. Окончив среднюю школу в 1952 г., он поступил на физико-математический факультет Горьковского государственного университета, который закончил в 1957 г. После завершения аспирантуры (1957-1960) он защитил в 1962 г. кандидатскую диссертацию на тему "Рождение перио-

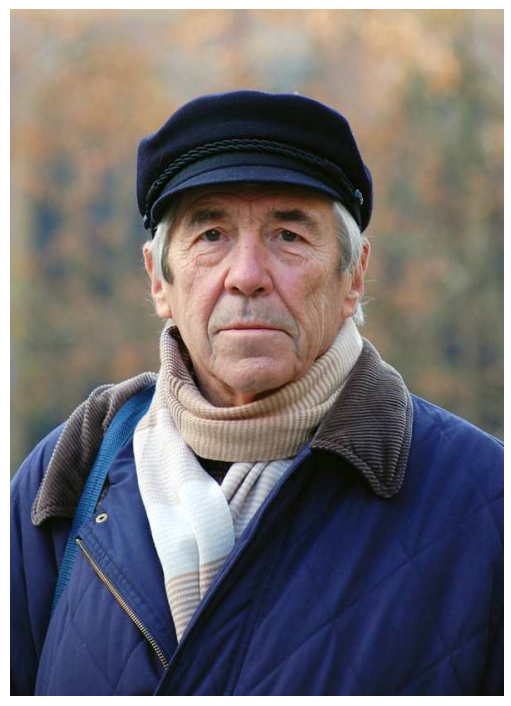
дических движений из особых траекторий”, где он обобщил на многомерный случай нелокальные бифуркации, изученные для систем на плоскости А. А. Андроновым и Е. А. Леонтович.

Вскоре после этого он занялся только зарождавшейся тогда теорией систем со сложной (хаотической) динамикой. К этому времени уже появился пример подковы Смейла (1961) и вышла заметка Д. В. Аносова (1962) о геодезических потоках, где было сформулировано понятие гиперболичности и выявлено его первостепенное значение. Развивая результаты диссертации, Л. П. Шильников обнаружил (ДАН, 1965), что бесконечное множество подков Смейла и, следовательно, сложная динамика существуют в окрестности гомоклинической петли седло-фокуса. Сегодня мы знаем, что шильниковская петля определяет хаотическую динамику широкого спектра моделей из разных областей естествознания. Однако для того времени результат о том, что сложная динамика возникает вблизи такого простого и привычного объекта, как петля сепаратрисы, был совершенно неожиданным. Л. П. Шильников понял, что изучение гомоклинических бифуркаций дает ему уникальную возможность для исследования сложной динамики многомерных систем, и это стало центральной темой его научной деятельности.

Уже в 1965-1967 гг. им было опубликовано полное решение классической, восходящей к Пуанкаре и Биркгофу задачи о структуре окрестности грубой гомоклинической кривой седлового периодического движения. Шильников считал этот результат особенно важным и не уставал подчеркивать, что грубая гомоклиника - основной "кирпичик" теории хаоса. Он не остановился на случае гомоклиники только к периодической 
траектории и сразу же опубликовал работу о структуре окрестности семейства траекторий, гомоклинических к инвариантному тору (в частности, к квазипериодическому движению). Позднее были изучены общий неавтономный и бесконечномерный случаи (совместно с Л. М. Лерманом). Для решения этих задач Шильников разработал "метод перекрестных отображений", который оказался к тому же очень удобным при получении асимптотических представлений решений системы в окрестности нелинейных седел и лег в основу исследований по теории гомоклинических бифуркаций.

Затем была серия работ, как самого Леонида Павловича, так и с учениками, в которой, по существу, был создан новый раздел теории динамических систем - теория глобальных бифуркаций. Все такие бифуркации были разбиты на три больших класса: бифуркации, не выводящие из класса систем Морса-Смейла; бифуркации от систем Морса-Смейла к системам со сложной динамикой; бифуркации в классе систем со сложной динамикой. Основные нелокальные бифуркации первого типа в многомерном случае были изучены самим Шильниковым. Им же были открыты и описаны нелокальные бифуркации второго типа: в частности, исторически первым примером бифуркации от систем Морса-Смейла к системам со сложной динамикой стала бифуркация букета гомоклинических петель состояния равновесия типа седло-седло (1969 г.). Позднее он вместе со своим первым учеником Н. К. Гавриловым начал изучать гомоклинические касания, а вместе с В.С. Афраймовичем периодические возмущения автономных систем с петлей сепаратрисы, разрушение инвариантных торов (т.е. явления перехода от двухчастотных режимов к хаосу) и бифуркации гомоклинических траекторий седло-узла (часть последних результатов с В.И. Лукьяновым). В этих работах были исследованы различные типы хаотического поведения и было обнаружено, что сложная динамика не описывается одними гиперболическими множествами - хаотические режимы очень часто соседствуют с устойчивыми. Позднее Л.П. Шильников предложил концепцию "квазиаттрактора" (притягивающего множества, которое наряду с гиперболическими подмножествами может содержать и устойчивые периодические траектории больших периодов) как наиболее адекватного математического образа динамического хаоса, наблюдаемого в прикладных задачах.

В то время системами со сложной динамикой заинтересовались физики и ученые из других областей. Вопрос о том, насколько открытый математиками динамический хаос нужен для естествознания, обсуждался весьма широко, и Л. П. Шильников принимал в дискуссиях активное участие. Поворотным моментом, как у нас, так и на Западе, - по сути, доказательством того, что динамический хаос есть одно из фундаментальных явлений природы, - стало открытие странного аттрактора в системе Лоренца. В отличие от гиперболических аттракторов, теория которых была уже хорошо развита, аттрактор Лоренца не сохраняет свою структуру при изменении параметров - в нем происходят бифуркации. Л.П. Шильников вспоминал, что как только он узнал об аттракторе Лоренца, ему стало ясно, что необходимые здесь методы теории бифуркаций уже созданы им и его школой. Он начал серию замечательных исследований по аттрактору Лоренца, выполненных совместно с В. С. Афраймовичем и В. В. Быковым. В этих работах (1977-1983 гг.) ярко проявилось глубокое понимание Леонидом Павловичем динамики и бифуркаций, умение создать адекватную математическую модель. Без этого было бы невозможно исследовать с такими деталями всю картину появления и исчезновения аттрактора, изменений его структуры при вариации параметров. По сей день теория Афраймовича-Быкова-Шильникова остается наиболее полной и удобной для практического анализа структуры и эволюции аттракторов типа Лоренца в различных моделях.

В 1982 г. Л. П. Шильников сменил Евгению Александровну Леонтович-Андронову в должности зав. отделом дифференциальных уравнений НИИ ПМК. Он возглавил работу дружного коллектива, к которому неформально примыкал сплоченный круг 
учеников и коллег. Руководимый Л. П. Шильниковым еженедельный семинар всегда был центром живых и острых дискуссий, выступать на нем было большой школой. Леонид Павлович часто умел найти нужные постановки задач даже в далекой от него области знаний, он отличался особой интуицией - многие коллеги отмечали, что общение с ним оказало огромное влияние на всю их научную карьеру. Он придавал большое значение пропаганде новых идей и открытий в теории динамических систем среди специалистов по радио- и биофизике, гидродинамике, метеорологии, был в числе организаторов нескольких конференций и школ по нелинейной тематике, сам активно выступал на таких конференциях. Специалисты из самых различных областей науки поддерживали и ценили тесные контакты с Леонидом Павловичем и его школой. Теплыми были его отношения с московскими и киевскими математиками В. М. Алексеевым, Д. В. Аносовым, Ю.С. Ильяшенко, А. Б. Катком, Е.Ф. Мищенко, А. М. Самойленко, Я.Г. Синаем, А.Н. Шарковским и многими другими. Когда после 1990 г. появились возможности выезжать за рубеж, Л. П. Шильникова стали приглашать с докладами на многочисленные международные конференции (включая Международный математический конгресс в Пекине) и в университеты США, Бельгии, Франции, Германии, Италии, Израиля, он стал членом редколлегий нескольких международных журналов. Много лет продолжалось сотрудничество с нобелевским лауреатом И. Р. Пригожиным и его коллегами, начавшееся с конференции "Гомоклинический хаос" (Брюссель, 1991), посвященной работам Л. П. Шильникова.

Л. П. Шильников особенно интересовался задачей о математическом описании бифуркационных сценариев возникновения турбулентности. Он опубликовал несколько работ на эту тему, в которых показал, как начальные локальные бифуркации регулярного динамического режима приводят к формированию геометрических структур, ответственных за последующие глобальные бифуркации и хаос. Другой, идущей от физики областью деятельности было исследование пространственного хаоса. Здесь в большой серии совместных работ с сотрудниками отдела и московскими физиками из группы В.М. Елеонского были изучены различные локальные и глобальные бифуркации в консервативных и гамильтоновых системах, построены локализованные решения нетривиальной структуры, открыт и изучен новый тип гомоклинических траекторий - гомоклиники к гомоклиническим петлям.

Главной темой научных исследований Л. П. Шильникова всегда оставались глобальные бифуркации и странные аттракторы. Вместе с сыном Андреем и Д. В. Тураевым им были продолжены исследования по аттрактору Лоренца. Был открыт новый класс многомерных странных аттракторов - дикие гиперболические аттракторы, т. е. притягивающие множества, включающие в себя гомоклинические касания, но не содержащие устойчивых траекторий. В цикле работ с С. В. Гонченко и Д. В. Тураевым было продолжено исследование гомоклинических касаний главным открытием, как считал сам Л.П. Шильников, явилось то, что бифуркации систем с квадратичными касаниями приводят к появлению гомоклинических касаний сколь угодно высокого порядка. Таким образом, было явно показано, что традиционная логика исследования бифуркаций по степени увеличения коразмерности, идущая от теории особенностей, не работает при изучении многих систем со сложной динамикой. В частности, если имеется гомоклиническое касание, то полное описание всех изменений в системе получить в принципе невозможно!

Одними из популярных среди специалистов по нелинейной динамике стали работы Л.П. Шильникова по так называемой катастрофе голубого неба. В свое время этот тип бифуркаций для потоков на двумерных поверхностях был обнаружен В. С. Медведевым. В исследованиях Л.П. Шильникова (совместно с Д. В. Тураевым, А.Л. Шильниковым, Н.К. Гавриловым) были построены новые многомерные примеры и развита общая теория таких бифуркаций, которые, как оказалось, могут приводить и к рождению нетривиальных гиперболических аттракторов. С приклад- 
ной точки зрения особенно интересно, что катастрофа голубого неба играет важную роль в динамике быстро-медленных систем, в частности, в динамике нейронов.

В общей сложности Л. П. Шильниковым опубликовано более 160 статей и несколько книг, включая двухтомник "Методы качественной теории в нелинейной динамике", написанный вместе с Д. В. Тураевым, Л. Чуа и А. Л. Шильниковым и вышедший на английском, русском и китайском языках. Он продолжал работать и заниматься наукой вплоть до своего ухода из жизни. В последних статьях он вновь вернулся к своей любимой теме - аттрактору Лоренца и его многомерным обобщениям.

Л. П. Шильников был одним из наиболее выдающихся специалистов в теории динамических систем, основателем теории глобальных бифуркаций. У него было много учеников, которые сами стали известными специалистами в теории динамических систем, и у них, в свою очередь, появились ученики. Под его руководством было защищено 16 кандидатских диссертаций, четверо его учеников стали докторами наук. Очень важное качество Леонида Павловича - его научная смелость. При решении важных, но трудных проблем он не поддавался соблазну следовать популярному или модному направлению, а шел своим путем, создавая новые методы исследований.

Л. П. Шильников был несомненным лидером нижегородской математической жизни, он был одним из инициаторов создания Нижегородского математического общества (1995) и его первым президентом. Основным местом работы Леонида Павловича был Институт прикладной математики и кибернетики при Нижегородском университете (до его организации в 1963 г. он работал в математическом отделе Горьковского исследовательского физико-технического института), где был последовательно старшим научным сотрудником, зав. лабораторией (с 1967 г.), и зав. отделом - с 1982 г. почти до конца жизни. Он также преподавал в Нижегородском университете, читал как регулярные, так и специальные курсы. Вплоть до последнего года он читал курс "Бифуркации многомерных динамических систем", который пользовался большой популярностью у студентов университета. K нему всегда шли сильные студенты, другие у него просто не могли бы работать. Попадая в его круг, человек сразу оказывался в необыкновенной атмосфере острого интереса к науке.

Леонид Павлович был живым и интересным человеком, прекрасным семьянином. Еще в университете он познакомился со своей будущей женой Людмилой Ивановной и, прожив с ней 55 лет, был неизменно ее верным спутником и другом, а для детей и внуков всегда оставался внимательным и любящим главой семьи, достойным уважения и подражания. Он очень увлекался историей, особенно историей науки, много читал на эти темы, очень любил футбол и был тонким его знатоком. Рыбалка на даче летом была его особой страстью.

Для нас Леонид Павлович останется большим ученым, учителем и замечательным человеком. Мы всегда будем помнить его, развивать его идеи и идти дальше в науке. Вечная ему память и огромное спасибо за все, что он сделал.

Д. В. Аносов, В.С. Афраймович, Л.А. Бунимович, С. В. Гонченко, В. З. Гринес, Ю.С. Ильяшенко, А.Б. Каток, С.А. Кащенко, В. В. Козлов, Л. М. Лерман, А.Д. Морозов, А.И. Нейштадт, Я. Б. Песин, А.М. Самойленко, Я.Г. Синай, Д. В. Трещёв, Д.В. Тураев, А.Н. Шарковский, А.Л. Шилъников 